\title{
Spanish Journal of Statistics: Welcome message from the new Editor-in-Chief
}

\author{
José María Sarabia \\ Department of Economics, University of Cantabria
}

\section{Introduction}

Welcome to the first issue of Spanish Journal of Statistics (SJS). This new scientific journal replaces Estadística Española, edited and published by the National Statistics Institute of Spain (INE) for more than 60 years. This journal has always been highly regarded by the Spanish scientific community and continues now with this trajectory of excellence, with a more international focus. The issues published can be found on the web-site of the SJS.

The papers to be considered in SJS must contain original theoretical contributions of direct or potential value in applications. Practical applications of methodological aspects are also welcome. The standards of innovation and impact are crucial in the papers published in SJS. Among the topics to be considered are: official Statistics; theory and methods; computation and simulation studies that develop an original methodology; critical evaluations and new applications; development, evaluation, review, and validation of statistical software and algorithms; reviews of methodological techniques; letters to the editor. All the information about the submission process can be found at: https://www.ine.es/sjs

\section{New challenges for SJS}

In the framework of today's digital society, the research agenda, both for modern statistical science and for official statistics, has substantially expanded with new topics and challenges. These new topics and aspects of statistical research include novel methodologies using different sources of information. In this sense, machine learning techniques, together with the corresponding computational tools, have successfully addressed many current data analysis problems.

To the traditional data sources of the surveys and administrative records, we have to add the widespread access to big data. Salgado (2017) discusses the challenges posed by big data within official statistics, including institutional access to data, the new statistical methodology for the treatment of this data and the changes in technological infrastructure.

The role of national statistical institutes and official statistics has become more prominent in recent years. According to Allin (2019): National statistical offices are not only providers of statistics; they should 
also provide answers to questions raised in society, recognizing that they have to compete for the attention of users. In this context, INE has tackled three important projects within the field of experimental statistics: the household income distribution atlas, the estimate of the number of weekly deaths during the COVID-19 outbreak and the analysis of the mobility of the population during the lockdown by COVID-19. Since these three statistical experiments are part of the strategy of the European Statistical System, their quality has already been assessed by different national statistical offices, besides Eurostat.

A relevant aspect of these projects is the use of the three types of sources: surveys, administrative records and big data. In an interesting contribution, Hand (2018) identifies some statistical challenges in the field of administrative and transaction data, providing a stimulating debate on how to improve the analysis of these types of sources. Torrecilla and Romo (2018) discuss the collection, storage, preprocessing and visualization of huge batches of data, using the terminology data learning for this scientific discipline.

\section{The new editorial board}

Our new editorial board consist of an experimented team of academics and researchers around the world. We currently have associated Editors from Australia, Brazil, Canada, Chile, Spain, Switzerland and the USA. The editorial team combines both specialists in statistical methodologies and official statistics.

\section{The first issue}

The first issue of this volume consists of two introductory notes and five papers.

The paper "Recovering income distributions from aggregated data via micro-simulations", by Ignacio Moral-Arce, Antonio de las Heras Pérez and Stefan Sperlich proposes a new methodology for the imputation of income densities corresponding to the observed grouped data. The paper introduces a method of density estimation from grouped data. Small sample properties and two empirical examples are presented.

The next four papers are devoted to contributions presented in a session organised by the Spanish Statistical Office, at the XII Public Statistics held in Alcoy (Alicante, Spain) in September 2019. The round table was focused on the "Spanish Living Conditions Survey" (ES-SILC) integrated into the European Statistics on Income and Living Conditions (EU-SILC). First, the paper by Agustín Cañada introduces the session, explaining its objectives within the "peer review" processes of the European Union, by which official statistical systems are subject to control and supervision of the degree of compliance with the European Statistics Code of Practice.

The paper by José María Méndez describes the main characteristics of the ES-SILC and the evolution of its methodology, from the initial version entirely based on sampling surveys, to the current methodology, which combines surveys with administrative sources.

Next, the paper by Alejandro Arias, Albert Arcarons and Amparo González compiles the applications of this survey by the Office of the High Commissioner to estimate child poverty in Spain. Moreover, the authors propose some recommendations for possible improvements of the EU-SILC survey, such as the introduction of labour market trajectories or information on daily living expenses, like education expenditures. 
Finally, Jorge Onrubia presents some possibilities of improving the Living Conditions Survey prepared by INE, in view of its upcoming reform, conceived within the updating process of the EU-SILC project promoted by Eurostat. The discussant reviews the inclusion of information from administrative registers, especially those from tax sources, as well as others from social security records.

\section{References}

Allin, P. (2019). Opportunities and challenges for official statistics in a digital society. Contemporary Social Science, DOI: 10.1080/21582041.2019.1687931.

Hand, D.J. (2018). Statistical challenges of administrative and transaction data. Journal of the Royal Statistical Society A, 181, 555-605.

Salgado, D. (2017). Big data en la Estadística Pública: retos ante los primeros pasos. (in Spanish) Economía Industrial, 405, 121-219.

Torrecilla, J.L., Romo, J. (2018). Data learning from big data. Statistics and Probability Letters, 136,15-19. 